\title{
Impact of Metabolic Syndrome And Metabolic Syndrome Components on Tumor Aggresiveness of Renal Cell Carcinoma
}

\author{
Ahmet Emin Dogan ${ }^{1}$, Ali Atan ${ }^{2}$, Ali Unsal ${ }^{2}$, Fazli Polat $^{2}$, and Suleyman Yesil ${ }^{3}$ \\ ${ }^{1}$ Health Sciences University Diskapi Yildirım Beyazit Training and Research Hospital \\ ${ }^{2}$ Gazi University Faculty of Medicine \\ ${ }^{3}$ Gazi Üniversitesi Tıp Fakültesi
}

August 2, 2021

\begin{abstract}
Objective: The objective of this study was to evaluate the effects of Metabolic Syndrome (MetS) and MetS components on tumor size, Fuhrman grade and pathological T stage in renal cell carcinoma (RCC). Materials and Methods: The data of 151 patients who were operated for RCC between January 2010 and April 2018 were retrospectively reviewed according to the he National Cholesterol Education Program Adult Treatment Panel III (NCEP ATP III), and the effects of MetS and its components on tumor size, Fuhrman grade and pathological $\mathrm{T}$ stage were comparatively investigated. Results: Of the 151 patients operated for RCC in our clinic, $27.2 \%$ had MS, $29.1 \%$ had diabetes mellitus (DM), 41\% had hypertension (HT), 68.3\% had low high-density lipoprotein (HDL), $41 \%$ had elevated triglyceride (TGL) elevation, and $27.2 \%$ had obesity. It was found that the size of the tumor was statistically significantly increased in the presence of the metabolic criteria examined. There was a statistically significant increase in the Fuhrman grade of the patients with MetS, DM, low HDL, high TGL and obesity. In the presence of clinical conditions such as HT, low HDL and high TGL, there was a statistically significant increase in the pathological $\mathrm{T}$ stage. Conclusion: In patients undergoing surgery for RCC, MetS and its components had a statistically significant correlation with tumor size, Fuhrman grade, and pathological stage. If our results are supported by further studies, the correlation between MetS and RCC could be revealed more clearly.
\end{abstract}

\section{Impact of Metabolic Syndrome And Metabolic Syndrome Components on Tumor Aggresive- ness of Renal Cell Carcinoma}

Objective: The objective of this study was to evaluate the effects of Metabolic Syndrome (MetS) and MetS components on tumor size, Fuhrman grade and pathological T stage in renal cell carcinoma (RCC).

Materials and Methods: The data of 151 patients who were operated for RCC between January 2010 and April 2018 were retrospectively reviewed according to the he National Cholesterol Education Program Adult Treatment Panel III (NCEP ATP III), and the effects of MetS and its components on tumor size, Fuhrman grade and pathological $\mathrm{T}$ stage were comparatively investigated.

Results: Of the 151 patients operated for RCC in our clinic, $27.2 \%$ had MetS, $29.1 \%$ had diabetes mellitus (DM), $41 \%$ had hypertension (HT), $68.3 \%$ had low high-density lipoprotein (HDL), $41 \%$ had elevated triglyceride (TGL) elevation, and $27.2 \%$ had obesity. It was found that the size of the tumor was statistically significantly increased in the presence of the metabolic criteria examined. There was a statistically significant increase in the Fuhrman grade of the patients with MetS, DM, low HDL, high TGL and obesity. In the presence of clinical conditions such as HT, low HDL and high TGL, there was a statistically significant increase in the pathological $\mathrm{T}$ stage.

Conclusion: In patients undergoing surgery for RCC, MetS and its components had a statistically significant 
correlation with tumor size, Fuhrman grade, and pathological stage. If our results are supported by further studies, the correlation between MetS and RCC could be revealed more clearly.

Keywords: Renal cell carcinoma, Metabolic Syndrome, Diabetes mellitus, Hypertension

\section{What's already known about this topic?}

Metabolic Syndrome causes increased incidence of prostate cancer and renal cell carcinoma.

\section{What does this article add?}

Metabolic Syndrome and its components had a statistically significant correlation with tumor size, Fuhrman grade, and pathological stage.

\section{Introduction:}

Metabolic Syndrome (MetS) is an endocrinopathy that starts with insulin resistance, accompanied by a range of systemic disorders such as glucose intolerance, diabetes mellitus (DM), abdominal obesity, dyslipidemia, hypertension (HT), and coronary artery disease (CAD) [1]. MetS is one of the most important health problems with increasing prevalence and awareness. Due to the increased prevalence of MetS in society, the number of studies on this subject has increased. The prevalence of MetS, which is considered to be an important health problem in developed and developing countries, varies depending on age and gender [2, 3].

Although MetS was previously thought to cause only cardiovascular problems, new data reveal that it occurs with some urological disorders. The prevalence of erectile dysfunction, infertility, stone disease, overactive bladder, benign prostatic hyperplasia has also increased in these patients. At the same time, its relationship with malignancy by causing angiogenesis and oxidative stress due to baseline insulin resistance has been revealed. It has been observed to increase the incidence and progression of cancers. MetS has also caused an increase in the incidence of prostate cancer and Renal Cell Carcinoma (RCC) [4-7].

RCC accounts for 2-3\% of all adult malignant masses and for $85-90 \%$ of malignant tumors of the kidney. RCC is the highest mortality rate among the urological malignancies. Although RCC ranks third after prostate and bladder cancer among urological cancers, it accounts for $40 \%$ of deaths due to urinary system cancers. Knowledge of the etiology of RCC plays an important role in understanding the onset of histological cancer and its progression to invasive cancer $[8,9]$. Although there is no definite data that MetS components are effective in the development of RCC, some studies have reported that especially high-calorie dietary habits and obesity have some roles in the development of RCC and some studies have reported that DM, HT, and hypertriglyceridemia are important in the development of RCC [10-13].

This study aimed to reveal which MetS components have more clinical significance to compare kidney tumor characteristics of patients with and without MetS and to determine clinically significant risk factors for patient groups.

\section{Materials and Methods:}

The renal tumor database of Gazi University, Medical Faculty Hospital, Department of Urology was retrospectively reviewed. This study was reviewed and approved by the medical ethics committee of Gazi University School Of Medicine on 9 July 2018 (approval number: 542). Patients younger than 18 years of age, those with a previous history of surgical operation due to kidney tumors, hereditary or family history of malignancy other than RCC were excluded from the study. After obtaining informed surgical consent, 151 patients who underwent radical or partial nephrectomy between 2010 and 2018 for kidney tumor were included in the study. Patient information was collected from patient files and the hospital automation system. The missing information was completed by reaching the patients or their relatives through their phones registered in the hospital system. MetS was defined based on the National Cholesterol Education Program Adult Treatment Panel-III (NCEP/ATP III) criteria [1]. These criteria are as follows: elevated serum TGL ([?]150 mg/dl), low HDL cholesterol ( $<40 \mathrm{mg} / \mathrm{dl}$ in males, $50 \mathrm{mg} / \mathrm{dl}$ in females), HT (systolic blood pressure [?]130 $\mathrm{mmHg}$ and/or diastolic blood pressure [?]85 mmHg), high fasting plasma glucose ([?]110 mg/dl), waist 
circumference [?]102 $\mathrm{cm}$ for males and [?] $80 \mathrm{~cm}$ for females. In the presence of 3 of these 5 criteria, patients are considered to have metabolic syndrome. In our study, the body mass index (BMI) of the patients was used instead of waist circumference. The patients were grouped based on the presence and absence of MetS, as well as the presence and absence of MetS components. The groups were analyzed according to age, gender, tumor size, pathological T stage, Fuhrman grade, high density lipoprotein (HDL) and triglycerid (TGL) levels, HT, and DM status. The American Joint Comittee on Cancer 2017 RCC tumor-node-metastasis (TNM) staging system was used for the pathological T stage, and the 2016 WHO classification of RCC subtypes was used for the histological subtype [14,15] .

\section{Statistical analysis:}

The Statistical Package for Social Sciences (SPSS) version 22.0 for Windows (SPSS Inc. Chicago, USA) software package was used for the statistical analysis of the study data. If the data were non-normally distributed, the Mann-Whitney U test was used for comparison of two groups, and the Kruskal-Wallis test was used for comparison of 3 groups and more. Pearson's chi-squared test, Fisher's chi-squared test, and Continuity Correction chi-square test were used for comparison of categorical variables among independent groups. The correlation between tumor size, Fuhrman grade, stage, and metabolic measurements was analyzed by Spearman's Correlation test. In this study, the level of statistical significance was set at $\mathrm{p}<0.05$.

\section{Results:}

Of the patients, $49(32.5 \%)$ were female and $102(67.5 \%)$ were male, with a mean age of $55.9 \pm 12.7$ years. The mean tumor size was $61.6 \pm 34.9$ millimeters. Of the patients in our study, $17(11.3 \%)$ had Fuhrman grade 1 tumors, $57(37.7 \%)$ had grade 2, $55(36.4 \%)$ had grade 3, and $22(14.6 \%)$ had Fuhrman grade 4 tumors. The pathological T stages of the patients were as follows: $93(61.6 \%)$ pT1, $16(10.6 \%)$ pT2, $38(25.2 \%)$ pT3, and $4(2.6 \%)$ pT4 (shown in Table 1).

Of the patients, $44(29.1 \%)$ had DM and $62(41.1 \%)$ had HT. The patients in the study had a mean HDL value of $42.4 \pm 10.0 \mathrm{mg} / \mathrm{dl}$, a mean TGL value of $146.8 \pm 74.8 \mathrm{mg} / \mathrm{dl}$, and a mean BMI value of $28.1 \pm 4.1 \mathrm{~kg} / \mathrm{m}^{2}$. Of the patients, $88(68.3 \%)$ low HDL, while $62(41.1 \%)$ had elevated TGL. The patients were grouped based on their BMI values, 34 patients $(22.5 \%)$ were in the normal weight category, 76 patients $(50.3 \%)$ were in the overweight category, and 41 patients $(27.2 \%)$ were in the obese category. Forty-one of the patients $(27.2 \%)$ in the study had MetS (shown in Table 2).

There was a statistically significant difference between the patients with and without MetS in terms of tumor size (p: 0.046) and Fuhrman grade (p: 0.002). The patients with MetS had a larger tumor size and higher Fuhrman grade than those without MetS. There was no statistically significant difference between the patients with and without MetS in terms of pathological T stage (p: 0.104) (shown in Table 3).

Regardless of the antidiabetic treatment received and the regulation of blood glucose, the patients in our study were grouped as patients with a diagnosis of DM and those without DM when they underwent surgery, and the groups were compared for tumor size, grade, and pathological T stage. The patients with DM had a statistically significantly larger tumor size (p: 0.017) and a higher Fuhrman grade (p: 0.005) than those without DM. Since none of the patients in our study had stage 4 DM, the pathological stage correlation between the patients with DM and those without DM could not be analyzed (AUD) (shown in Table 4).

There was a statistically significant difference between the patients with a diagnosis of HT and those without a diagnosis of HT in terms of tumor size (p: 0.007), and pathological T stage (p: 0.007). The patients with HT had a statistically significantly larger tumor size and more advanced stage than those without HT. There was no statistically significant difference between the patients with a diagnosis of HT and those without a diagnosis of HT in terms of Fuhrman tumor grade (p: 0.067) (Table 4).

The patients in our study were grouped based on their dyslipidemia status and, patients with low HDL according to the MetS criteria and those without low HDL and patients with high TGL and those without high TGL were compared. The patients with low HDL had a statistically significantly larger tumor size (p: 0.006 ), a higher grade (p: 0.012), and a more advanced pathological T stage (p: 0.007) than those with low 
HDL. The patients with elevated TGL had a statistically significantly larger tumor size (p: 0.003), a worse Fuhrman grade (p: 0.010), and a more advanced pathological T stage (p: 0.010) than those without elevated TGL (shown in Table 5).

In our study, the BMI measurements of the patients when they underwent surgery were used instead of obesity, and the patients were grouped as normal weight, overweight, and obese based on their BMI values. There was a statistically significant difference between the patients grouped in terms of tumor size (p: 0.005 ) and tumor grade (p: 0.003). Since there were no obese pathological stage 4 patients in the study, the pathological stage correlation between obese patients and non-obese patients could not be evaluated (AUD) (shown in Table 6).

\section{Discussion:}

With the increasing prevalence of MetS, the number of studies on MetS etiology and MetS -related diseases has also increased. Considering that MetS and its components should be evaluated in a broader spectrum, a concept termed metabesity has been introduced with the increasing recognition of their relationship with cancer [16]. In our study, it was concluded that the patients with MetS had a larger tumor size and a higher Fuhrman grade than those without MetS, but there was no difference between the two groups in terms of the pathological stage.

There are many studies examining the relationship between DM and RCC. It is still controversial whether DM itself or DM-related diseases increase the risk of RCC [17]. Some autopsy studies have found an increased prevalence of DM in patients with kidney cancer $[18,19]$. Compared to the general population, the morbidity and mortality of RCC increases in patients with DM. Type 2 DM has been shown to be associated with an increased risk of RCC in women [20,21]. DM has also been found to have a negative effect on disease progression and recurrence, and a significant difference has been determined in 5-year recurrence-free survival between patients with and without DM. It has been determined that preoperative high hemoglobin A1c predicts postoperative progression [22, 23]. There are studies showing that patients with DM have a significantly higher Fuhrman grade and a larger tumor size than patients without DM. Metformin, one of the common oral anti-diabetic drugs, can inhibit the growth of RCC cells in vivo and in vitro. Several studies have demonstrated the inhibitory effect of metformin on many tumor cells, including RCC cells [24-26]. Contrary to these studies, Habib et al. found that the tumors of patients with DM tended to be smaller in size and there was no relationship between blood glucose level and tumor size [27]. In our study, a statistical difference was found between the patients with a diagnosis of DM and those without a diagnosis of DM in terms of tumor size and Fuhrman grade, but the correlation between pathological $\mathrm{T}$ stages could not be analyzed.

HT, one of the MetS components, is another risk factor. It has been confirmed by numerous clinical studies that HT can increase the risk of RCC $[28,29]$. Although the etiopathogenesis of this increased risk is not completely known, renal damage, inflammation, and increased susceptibility to carcinogens secondary to $\mathrm{HT}$ are thought to increase the risk of RCC [30]. In the literature, there are also studies showing that antihypertensive treatment increases the risk of RCC [31]. However, there is a need for large-scale studies to clarify the effect of especially diuretic-like antihypertensive drugs on the development of RCC. In our study, the patients with a diagnosis of HT and those without a diagnosis of HT at the time of surgery were compared for tumor size, tumor grade, and stage, regardless of the duration of having HT, the type of medication received, and the blood pressure levels. Although it was found that the patients with a diagnosis of HT had a larger tumor size and a higher pathological T stage, there was no significant difference between the patients with and without a diagnosis of HT in terms of Fuhrman grade.

There are many studies showing that dyslipidemia, one of the components of MetS, plays a role in the development of various cancers. The relationship between high TGL and esophageal and colon cancer has been demonstrated in the literature [32,33]. The fact that clear cell RCC, the most common type of RCC, is histologically characterized by sterol accumulation in tumor cells suggests that lipid metabolism is effective in the formation and progression of RCC. Statins commonly used for the treatment of lipid disorders, especially 
hypercholesterolemia, have been reported to provide protection against the development of RCC and have an inhibitory effect on tumor growth, invasion, angiogenesis, and metastasis in vitro. Experimental evidence shows that deregulated cholesterol and lipid biosynthesis plays an important role in the development of RCC $[34,35]$. Contrary to these studies, there are also studies showing lower cancer incidence and mortality in patients with high serum TGL levels, as well as studies showing the existence of a relationship between low cholesterol levels and increased cancer incidence [36-38]. According to the results of our study, both patients with low HDL and patients with elevated TGL had a statistically significantly larger tumor size, higher Fuhrman grade, and more advanced pathological T stage than those with low HDL and those without elevated TGL.

Obesity is a risk factor for $\mathrm{RCC}$ and there is a relative increase in RCC risk in direct proportion to the severity of obesity, especially in women. It has not yet been definitively demonstrated how obesity increases the risk of kidney cancer [39, 40]. Currently, there are studies showing that an increased BMI in both genders and being overweight in late adolescence are effective in the development of RCC [41, 42]. Contrary to these studies, Parker et al. found that patients with a high BMI tended to have less aggressive tumors [43]. In our study, obese patients had a larger tumor size and a worse Fuhrman grade, but no interpretation could be made about the pathological stage.

In conclusion, it was found that patients with MetS or the components of DM, HT, low HDL, elevated TGL, and obesity had a statistically significantly larger tumor size, and patients with MetS or DM and obese patients had a worse Fuhrman grade, while patients with HT had a more advanced pathological stage. Since there were no patients with DM or obese patients with pathological stage 4 in the study, no interpretation could be made about the relationship between DM, obesity, and the pathological stage. Patients with dyslipidemia were found to have a larger tumor size, a worse Fuhrman grade, and a more advanced pathological stage. Based on these data, the worst effect is seen in the presence of dyslipidemia in terms of a single component. If these results are supported by similar studies, the relationship of MetS and its components with RCC will be revealed more clearly.

Conflict of Interest: No conflict of interest was declared by the author.

Financial Disclosure: The author declared that this study has received no financial support

\section{References:}

1. Cholesterol Education Program (NCEP) Expert Panel on Detection, Evaluation, and Treatment of High Blood Cholesterol in Adults (Adult Treatment Panel III) final report. Circulation 2002;106:3143421.

2. Grundy SM. Metabolic syndrome pandemic. Arterioscler Thromb Vasc Biol 2008; 28: 629-36.

3. Zimmet P, Magliano D, Matsuzawa Y, Alberti G, Shaw J. The metabolic syndrome: a global public health problem and a new deinition. J Atheroscler Thromb 2005; 12: 295- 300.

4. Colangelo LA, Gapstur SM, Gann PH, Dyer AR, Liu K: Colorectal cancer mortality and factors related to the insulin resistance syndrome. Cancer Epidemiol Biomarkers Prev 2002, 11:385-391.

5. Hammarsten and Peeker R. Nat Rev Urol. Urological aspects of the metabolic syndrome. 2011; 8 : 483-94

6. Gorbachinsky et al. Rev Urol. Metabolic syndrome and urological diseases. 2010; $12: 157-80$

7. Chu et al. Postgrad Med. The impact of obesity on benign and malignant urologic conditions 2013; 125 : 53-69

8. Motzer Rj, Agarwal N, Beard C, et al. Kidney cancer clinical practice guidelines in oncology. J Natl Compr CAnc Netw 9:960-977,2011

9. Campbell SC, Lane BR. Malignant renal tumors. In: Kavoussu LR, Novick AC, Partin AW, Peters CA, eds. Campbell-Walsh Urology. 10th ed. Philedelphia: Saunders 2012; 1413.

10. Cowey S, Hardy RW. The metabolic syndrome: a high-risk state for cancer? Am J Pathol 2006;169:150522.

11. Choi Y, Park B, Jeong BC, Seo SI, Jeon SS, Choi HY, et al. Body mass index and survival in pa- 
tients with renal cell carcinoma: A clinical-based cohort and meta-analysis. Int J Cancer 2013 Feb 1;132(3):625-34

12. Lipworth L, Tarone RE, Lund L, McLaughlin JK. Epidemiologic characteristics and risk factors for renal cell cancer. Clin Epidemiol 2009;1:33-43.

13. Navai N, Wood CG. Environmental and modifiable risk factors in renal cell carcinoma. Urol Oncol 2012;30:220-4.

14. Robson CJ. Staging of renal cell carcinoma. Prog Clin Biol Res. 1982;100:439-45.

15. Edge SB, American Joint Committee on Cancer. AJCC cancer staging manual. Eighth edition. ed. xvii, 1,024 pages $\mathrm{p}$

16. Atan A. Metabesity and urological cancers. Turk J Urol. 2017 Dec;43(4):410-413. doi: 10.5152/tud.2017.66502. Epub 2017 Dec 1. Review.

17. Zucchetto A, Dal Maso L, Tavani A ve ark. History of treated hypertension and diabetes mellitus and risk of renal cell cancer. Ann Oncol 2007; 18: 596-600.

18. Hajdu SI, Thomas AG (1967) Renal cell carcinoma at autopsy. J Urol 97: $978 \pm 982$

19. Whisenand JM, Kostas D, Sommers SC (1962) Some Host Factors in the Development of Renal Cell Carcinoma. West J Surg Gynecol 70: 284 285

20. Lindblad $\mathrm{P}$, Chow WH, Chan J, et al. The role of diabetes mellitus in the aetiology of renal cell cancer. Diabetologia 1999, 42:107-112.

21. Joh HK, Willett WC, Cho E: Type 2 diabetes and the risk of renal cell cancer in women. Diabetes Care 2011, 34:1552-1556.

22. Lee H, Kwak C, Kim HH, et al. Diabetes mellitus as an independent predictor of survival of patients surgically treated for renal cell carcinoma: A propensity score matching study. J Urol. 194:1554-1560. 2015.

23. Fukushima H, Masuda H, Yokoyama M, et al. Diabetes mellitus with obesity is a predictor of recurrence in patients with non-metastatic renal cell carcinoma. Jpn J Clin Oncol. 43:740-746. 2013.

24. Otunctemur A, Ozbek E, Sahin S, et al. Diabetes mellitus as a risk factor for high grade renal cell carcinoma. Asian Pac J Cancer Prev. 2014;15(9):3993-6

25. Li M, Liu J, Hu WL, et al. Effect of metformin on apoptosis of renal cell carcinoma cells in vitro and its mechanisms. Nan Fang Yi Ke Da Xue Xue Bao 2011, 31:1504-1508.

26. Liu J, Li M, Song B, et al. Metformin inhibits renal cell carcinoma in vitro and in vivo xenograft. Urol Oncol 2013, 31:264-270.

27. Habib SL, Prihoda TJ, Luna M, Werner SA (2012). Diabetes and risk of renal cell carcinoma. J Cancer $, 3,42-8$.

28. Chow WH, Gridley G, Fraumeni JF Jr, Jarvholm B: Obesity, hypertension, and the risk of kidney cancer in men. N Engl J Med 2000, 343:1305-1311.

29. Colt JS, Schwartz K, Graubard BI,et al. : Hypertension and risk of renal cell carcinoma among white and black Americans. Epidemiology 2011, 22:797-804.

30. Lipworth L, Tarone RE, McLaughlin JK. The epidemiology of renal cell carcinoma. J Urol. 2006 Dec;176(6 Pt 1):2353-8.

31. Grossman E, Messerli FH, Goldbourt U: Does diuretic therapy increase the risk of renal cell carcinoma? Am J Cardiol 1999, 83:1090-1093

32. Wulaningsih W, Garmo H, Holmberg L,et al. Serum Lipids and the Risk of Gastrointestinal Malignancies in the Swedish AMORIS Study. J Cancer Epidemiol 2012, 2012:792034.

33. Inoue M, Noda M, Kurahashi N, et al.Impact of metabolic factors on subsequent cancer risk: results from a large-scale population-based cohort study in Japan. Eur J Cancer Prev 2009, 18:240-247.

34. Horiguchi A, Ito K, Sumitomo M, et al. Decreased serum adiponectin levels in patients with metastatic renal cell carcinoma. Jpn J Clin Oncol 2008, 38:106-111.

35. Drabkin HA, Gemmill RM (2012) Cholesterol and the development of clear-cell renal carcinoma. Curr Opin Pharmacol 12(6):742-750

36. Eichholzer M, Stahelin HB, Gutzwiller F, et al. (2000). Association of low plasma cholesterol with mortality for cancer at various sites in men: 17-y follow-up of the prospective Basel study. Am J Clin 
Nutr , 71, 569-74.

37. Bowers K, Albanes D, Limburg P, et al (2006). A prospective study of anthropometric and clinical measurements associated with insulin resistance syndrome and colorectal cancer in male smokers. Am $J$ Epidemiol , 164, 652-64.

38. Meilahn EN, Ferrell RE. 'Naturally occurring' low blood cholesterol and excess mortality. Coron Artery Dis 1993;4:843-53.

39. Bjørge T, Tretli S, Engeland A. Relation of height and body mass index to renal cell carcinoma in two million Norwegian men and women. Am J Epidemiol. 2004 Dec 15;160(12):1168-76.

40. Pischon T, Lahmann PH, Boeing H, et al. Body size and risk of renal cell carcinoma in the European Prospective Investigation into Cancer and Nutrition (EPIC). Int J Cancer. 2006 Feb 1;118(3):728-38.

41. Haggstrom C, Rapp K, Stocks T et al. Metabolic factors associated with risk of renal cell carcinoma. PLoS One 2013;8:e57475.

42. Leiba A, Kark JD, Afek Adolescent obesity and paternal country of origin predict renal cell carcinoma: a cohort study of 1.1 million 16 to 19-year-old males. J Urol 2013, 189:25-29.

43. Parker AS, Lohse CM, Cheville JC, et al (2006). Greater body mass index is associated with better pathologic features and improved outcome among patients treated surgically for clear cell renal cell carcinoma. Urol , 68, 741 .

\section{Hosted file}

Table 1.docx available at https://authorea.com/users/428780/articles/532585-impact-ofmetabolic-syndrome-and-metabolic-syndrome-components-on-tumor-aggresiveness-of-renalcell-carcinoma

\section{Hosted file}

Table 2.docx available at https://authorea.com/users/428780/articles/532585-impact-ofmetabolic-syndrome-and-metabolic-syndrome-components-on-tumor-aggresiveness-of-renalcell-carcinoma

\section{Hosted file}

Table 3.docx available at https://authorea.com/users/428780/articles/532585-impact-ofmetabolic-syndrome-and-metabolic-syndrome-components-on-tumor-aggresiveness-of-renalcell-carcinoma

\section{Hosted file}

Table 4.docx available at https://authorea.com/users/428780/articles/532585-impact-ofmetabolic-syndrome-and-metabolic-syndrome-components-on-tumor-aggresiveness-of-renalcell-carcinoma

\section{Hosted file}

Table 5.docx available at https://authorea.com/users/428780/articles/532585-impact-ofmetabolic-syndrome-and-metabolic-syndrome-components-on-tumor-aggresiveness-of-renalcell-carcinoma

\section{Hosted file}

Table 6.docx available at https://authorea.com/users/428780/articles/532585-impact-ofmetabolic-syndrome-and-metabolic-syndrome-components-on-tumor-aggresiveness-of-renalcell-carcinoma 